W. Schwarz $\cdot$ C. Willy $\cdot$ C. Ndjee $\cdot$ H. Gerngroß

\title{
Schwerkraft- oder Saugdrainage in der Schilddrüsenchirurgie?
}

Effizienzkontrolle mittels sonographischer Resthämatombestimmung

Langenbecks Arch Chir (1996) 381:337-342

High-vacuum or passive drains in thyroid surgery? Efficiency control by ultrasonographic measurement of resting hematoma

Irrtümlich wurde H. Gerngroß als Mitverfasser aufgeführt.

Die Autorenzeile lautet wie folgt:

W. Schwarz $\cdot$ C. Willy $\cdot$ C. Ndjee 